\title{
INTERSECCIONALIDADE, DOCUMENTAÇÃO E VIOLÊNCIAS
}

\author{
INTERSECTIONALITY, DOCUMENTATION AND VIOLENCE \\ INTERSECCIONALIDAD, DOCUMENTACIÓN Y VIOLENCIAS
}

Rebecca Lemos Igreja

Doutora em Antropologia

Universidade de Brasília

Brasil

Maria Teresa Sierra Camacho

Doutora em Sociologia

Centro de Investigaciones y Estudios Superiores en Antropología Social

México

Talita Rampin

Doutora em Direito

Universidade de Brasília

Brasil

Fernando Antônio de Carvalho Dantas

Doutor em Direito

Universidade Federal de GoiáS

Brasil

\section{Resumo}

Editorial do primeiro número, quarto volume, da revista "Abya Yala -Revista sobre acesso à justiça e direitos nas Américas".

Palavras-chave: Acesso à justiça, direito, Américas.

\section{Resumen}

Editorial del primer número del cuarto volumen, de la revista "Abya Yala -Revista sobre acceso a la justicia y derechos en las Américas".

Palabras clave: Acceso a la justicia, derecho, América.

\section{Abstract}

Editorial of the first issue of the fourth volume, of the magazine "Abya Yala -Journal on access to justice and rights in the Americas".

Keywords: Access to justice, law, Americas. 
1

bya-Yala: revista sobre acesso à justiça e direitos nas

Américas, publiciza seu quarto volume, de 2020, pelo qual divulga o dossiê «Interseccionalidad, Documentación y Violencias: Mujeres Indígenas y Afrodescendientes de las Américas ».

O Dossiê é organizado por Dolores Figueroa Romero, catedrática CONACYT adscrita al Centro de Investigaciones y Estudios Superiores en Antropología Social (CIESAS) en la Ciudad de México, y por Natalia De Marinis, profesora investigadora del CIESAS, sede Golfo, às quais agradecemos pela parceria e colaboração, e registramos nosso reconhecimento pela qualidade do trabalho realizado, assim como, seu comprometimento com estudos e perspectivas interseccionais e comparadas.

A edição conta com oito artigos e, ainda, com o registro do testemunho de Rubi Alondra. Gostaríamos de agradecer, nominalmente, a cada uma das mulheres que participam dessa construção coletiva: Arelly Mabell Barbeyto Rodríguez, Dolores Figueroa Romero, Katy Cedeño, Maria Teresa Sierra, Marisol Alcocer Perulero, Natalia De Marinis, Nora Sánchez, Norma Don Juan, Patricia Torres
Sandoval, Paulina García-Del Moral, Perla Orquídea Fragoso Lugo, Rubí Alondra, Selmira Flores y Vivian Jimenez-Estrada.

Em um ano marcado por uma pandemia histórica que reforçou a necessidade de fortalecermos nosso engajamento com a transformação da realidade, acreditamos que essa edição reforça nosso compromisso em divulgar e denunciar as relações de opressão, dominação e espoliação que marcam nossa história.

Aproveitamos para agradecer, igualmente, as contribuições de nosso Conselho Editorial e corpo de pareceristas.

Desejamos a todas e todos uma excelente leitura!

Rebecca Lemos Igreja

Maria Teresa Sierra Camacho Talita Rampin

Fernando Antônio de Carvalho Dantas 